\title{
A Comparative Study on Research Strategies for the Architectural Design Evaluation
}

\author{
Seung-Hoon Han and Jin-Woo Moon \\ School of Architecture, Chonnam National University, Gwangju, Korea \\ Corresponding Author, Biohousing Research Institute, Chonnam National University, Gwangju, Korea
}

\begin{abstract}
The aim of this paper is to evaluate the methodological strategies for the architectural design field of study mainly focused on qualitative and quantitative research designs. Firstly, this paper addresses the characteristics of the six approaches including their methodological aspects in general. Each strategy is assessed by the different approaches to give full insights in it. Secondly, it distinguishes the differences among six research approaches especially derived from qualitative and quantitative research designs. The differences are discussed in terms of the strengths and weaknesses of each strategy. Finally, this paper attempts to discuss about possible applications for introducing approaches to the research topic with which the exemplified research topic, a design evaluation system, deals. To investigate the applicability of the design methods employed, the following topic has been stated; how to develop a design evaluation system and what to be considered for unfolding the thrown topic in terms of strategic approaches in the field of architectural design researches reviewed through the study.
\end{abstract}

Keywords : Research Design, Research Methodology, Comparative Study, Qualitative Research, Quantitative Research

\section{INTRODUCTION}

To accomplish a research objective, it is normally necessary to gather information on the interaction between related research designs on thrown research questions and design process. The aim of this paper is to evaluate the research designs to be used in the area of architectural research.

The first part addresses the characteristics of the six different approaches, such as experimental, correaltional, qualitative, interpretive, theoretical, and simulation, including their commonalties and methodological aspects in general. The second and third parts distinguish the differences among the research designs. The differences are discussed in terms of the strengths and weaknesses of each strategy. The final part attempts to apply for both approaches to the research topic with which an exemplified research topic will deal. Each research design will be focused on the issue of research goal, system of inquiry, the assessment of research quality, and the appropriateness of strategies and tactics.

To discuss about the applicability of the design methods to the field of architectural design research, it is needed to assume that there is a composite topic to resolve the research questions, such as developing a design evaluation system to promote a general prototype for the typical architectural design process. This research is also assumed to use an exemplar for a design evaluation system by combining researches on integrated qualitative approaches in terms of employing relative theories with quantitative tools.

\section{(1) Problem Statement}

The architectural design process can normally be divided into the following phases: pre-design, schematic design, decision-making and design optimization, design development, construction documents, bidding, and administration of the construction (McGinty, 1979). Informa- tion used for design optimization and development is collected from various sources, organized and conceptualized in the pre-design stage. In the schematic design phase, the overall characteristics of the building are established, and significant issues are identified, and initial design decisions are made. The decision-making and design optimization phase is an iterative process during which design proposals are presented for review by client, project participants, review boards composed of experts from various fields, or a design jury; and, through communications and collaborations among them, design decisions are finalized.

During the design development phase, following the approval of the design, the specific character and intent of the entire project are described, details are developed and construction documents are produced. These may be a combination of working drawings and written specifications which serve as a legal description of what is to be built. As the construction documents near completion, they are released for bidding, and a contractor is selected. The final phase of the design process is the one in which the architect administers the construction, interpreting changes and judging performance.

Throughout all of these phases, architects are involved in a variety of tasks ranging from the most creative to the relatively pedestrian. The use of design technology has grown over the decades, and has been involved in the automation of tasks and in the management of information, especially in the later phases of the design process. Design technology has, however, had comparatively little impact on the earlier phases of design; there is a point in the design process when architects and designers must make a cognitive leap from pre-design sketches and study models to the final representations (Lansdown, 1994).

\section{(2) Exemplar for the Study}

Accordingly, the needs of direct collaboration among project participants situated in different locations is also 
emphasized in the early design stage in order to not only save time and provide places to meet and talk, but also to save cost for those events as well. Given the above design process scenario, this study will investigate how architects can use today's design evaluation methods for collaborations in the early design stages, and to gain insight into the advantages and shortcomings of such an approach. From this insight, it is envisioned that specific recommendations will be made for a development of design evaluation systems using design technology application.

For this research, shared interactive design information modeler has been considered as an exemplar for an evaluation application system which is specifically designed to meet the requirements of the recent architectural collaborative design process, and relevant research strategies based on design simulations has been followed to reveal the characteristics of the assumed research design methods. In this paper, each chapter will explain each representative research strategy involved into the suggested topic above, and show how it is developed for the architectural design evaluation.

\section{EXPERIMENTAL AND CORRELATIONAL RE- SEARCH APPROACHS}

Both experimental and correlational researches may be characterized as quantitative research strategies. Quantitative research is normally conceptualized for causal inquiry or prediction and control. At the same time, researchers try to maintain objectivity using research instruments to detach themselves from the phenomenon under investigation. Objective and well-structured methods such as statistical analysis are used to verify results, and are also a subject to scrutiny and cross-examination by the research community (Blalock, 1960). In other words, the other group of researchers can replicate the study to further verify its validity and reliability.

An experimental research typically involves four components: independent variables, dependent variables, comparison, and units of assignment. The independent variables $^{1}$ are presumed to be the possible causes and are directly manipulated by the researcher in an experiment. Possible effects of the treatments are referred as dependent variables $^{2}$, which are subject to measures taken before, during or after an experiment (Cook and Campbell, 1979). To infer treatment effects, one needs a comparison. Experimental design typically uses one or more control groups not receiving the treatment as a baseline to compare the results of the treatment. The comparison is then critical for detecting effects and for attributing them to the treatments. The units of assignment should provide the greatest sensitivity that the effect on the outcome is actually due to the experimental manipulation in the study.

\footnotetext{
${ }^{1}$ The independent variable in an experimental research is also referred to as the experimental or the treatment variable.

${ }^{2}$ The dependent variable is also known as the criterion outcomes of the study.
}

Experimental design can be categorized into preexperimental, true experimental and quasi-experimental according to the manner of assignment and the use of control group. With pre-experimental designs, the research does not have a control group to compare with the experimental group. In true experimental, the subjects are assigned randomly to treatment groups. It means that every individual who is participating in the experiment has equal chance of being assigned to any of the experimental or controlled condition that are being compared. In quasiexperimental, some but not all relevant variables are under control and subjects are not randomly assigned to the groups (Creswell, 1994).

The objective of correlational design is to investigate the extent to which variations in one factor correspond with variations in one or more other factors. It offers the opportunity to establish relationships or associations among variables. Correlational design is appropriate where variables are very complex and do not lend themselves to the experimental method and controlled manipulation. In most correlational studies, measures of different levels of several variables are taken as they occur naturally, without any experimental intervention (Isaac and Michael, 1981).

In sum, both experimental and correlational research designs are quantitative strategies in that the amount of variations in variables is quantitatively manipulated, measured and analyzed. Statistical instruments are employed in data analyses in order to determine the relationship among variables.

Table 1. Comparison of Characteristics between Experimental and Correlational Research Strategies

\begin{tabular}{c|l}
\hline \multicolumn{1}{c|}{ Experimental } & \multicolumn{1}{c}{ Correlational } \\
\hline $\begin{array}{l}\text { - Aims at Identifying causal } \\
\text { links as explanation. }\end{array}$ & $\begin{array}{l}\text { Aims at predicting consistent } \\
\text { patterns or degree of relationships } \\
\text { among variables. } \\
\text { experimental, true experimental } \\
\text { and quasi-experimental. }\end{array}$ \\
$\begin{array}{l}\text { - Manipulates variables di- } \\
\text { structured interview and content } \\
\text { analysis, etc. }\end{array}$ \\
$\begin{array}{l}\text { - Uses predetermined vari- } \\
\text { assure equal chance of assigning } \\
\text { variables. }\end{array}$ \\
$\begin{array}{l}\text { ables. Enables variables to vary } \\
\text { freely. No manipulation of variables } \\
\text { is required. }\end{array}$ \\
\hline
\end{tabular}

\section{(1) Comparison of Strengths}

The peculiar advantage of experimental design is that it permits interpretation of the causal direction of relationship; whether controlled exposure to differences in one variable is accompanied by subsequent differences in the second variable. As Crano and Brewer suggested in their book, Principle of Research in Social Psychology, "the major purpose of experimental research is to eliminate or control alternate explanations of change in the dependent variable." In well-controlled laboratory experiments, causal inference may be guaranteed by keeping out extraneous or irrelevant forces that could affect the outcome of an experiment and lead to spurious causal inferences (Crano and Brewer, 1973).

In addition, in experimental design, there is a clear dis- 
tinction between the independent variable manipulated by the researcher and the dependent variable which is allowed to vary freely. However, in many areas of research interest such as social psychology and behavioral science, experimental control over relevant variables is either impossible, or at least, completely impractical. What we should remind is, as pointed out by Crano and Brewer, "such variables can enter an experimental design never as experimental treatments, but only as control factors."

While the experimental method deals with the phenomena of cause and effect within a closed system of controlled conditions, the correlational design aims to investigate more complicated relationship among variables, especially in social or behavioral science, the situation of which may be inherently complex. As Crano and Brewer mentioned, "the major advantage of correlational research design is that it permits the free variation of several variables simultaneously and in a realistic setting, so that the relationship between them can be determined without the loss of data inherent in the experimental design." Some statistical methods of correlational analysis not only provide information on the extent of the relationship between the two variables being measured, but also may indicate both the degree and type of this relationship.

Correlational research can be more useful in exploratory research as a basis for the type of investigation. As opposed to the experimental research, correlational research approach enables researchers to systematically seek the relationship of variables in the real world situation. I think this point is very important for architectural research in social scientist's point of view, because human behaviors may be different if they are intentionally restricted.

On the other hand, the experiment can be a valuable tool for hypothesis-testing research dealing with predictions derived from some empirical or conceptual framework, because the high level controls in experiment effectively rule out other alternative explanations for the change in the dependent variable. In correlational research designs, although an observed relationship between two measures can serve a valuable function for theory, the finding can only be supportive, since the possibility that the correlation is due to some factors irrelevant to the theory can never be eliminated (Crano and Brewer, 1973).

Table 2. Comparison of Strengths between Experimental and Correlational Research Strategies

\begin{tabular}{l|l}
\hline \multicolumn{1}{c|}{ Experimental } & \multicolumn{1}{c}{ Correlational } \\
\hline $\begin{array}{l}\text { key variables. } \\
\text { Allows researchers to estab- }\end{array}$ & $\begin{array}{l}\text { - Enables variables to vary. } \\
\text { plore complexity of the relationship } \\
\text { among variables. } \\
\text { lish causality between independent } \\
\text { and dependent variables. } \\
\begin{array}{l}\text { - Eliminates extraneous vari- } \\
\text { ables. }\end{array}\end{array}$ \\
$\begin{array}{l}\text { is the relationship between the } \\
\text { whole range of independent and } \\
\text { dependent variables. }\end{array}$ \\
\hline
\end{tabular}

\section{(2) Comparison of Weaknesses}

The major disadvantage of experimental research is concerned with the external validity or generalizability.
For instance, when the study is performed in a laboratory or controlled setting, the generalizability of results to a real world setting will be limited, because the real life situation is more complicated and involves various kinds of variables different from the laboratory or controlled environment (Cook and Campbell, 1979).

Another negative effect of control is that, while experimental design allows one to focus observations on a small number of attributes at one time, researchers may lose the big picture and fail to fully account for the whole situation under study (Cook and Campbell, 1979).

In true experimental designs, random assignment of units seems one of the greatest guarantees of validity. However, real-world life presents certain situations where random selection and assignment are impractical or impossible. Such experiments, carried out under conditions where it is impossible to guarantee randomness, tend to rely on quasi-experimental designs. In such design, as Cook and Campbell suggested, "it is imperative that the researcher be thoroughly aware of the specific variables the design fails to control and to take these into account in the analysis and interpretation of the data".

On the other hand, the main problem with the validity of correlational analyses is that the variables usually accompanied with natural covariates, and the relational patterns between two variables are often ambiguous and difficult to determine (Crano and Brewer, 1973). Because most covariates cannot be extricated through cross-classification, there has been a temptation among behavioral scientists to substitute correlational analyses for experimental control in attempts to classify the factors with variables. These attempts cause an inadequate understanding of the context within which correlational approaches have been developed.

Table 3. Comparison of Weaknesses between Experimental and Correlational Research Strategies

\begin{tabular}{|c|c|}
\hline Experimental & Correlational \\
\hline $\begin{array}{l}\text { Has limited manipulation of } \\
\text { independent variables and varia- } \\
\text { tion of dependent variables due to } \\
\text { the restriction of controlled envi- } \\
\text { ronment. } \\
\text { - Lacks generalizability or ex- } \\
\text { ternal validity. That is, results of } \\
\text { the study in a controlled environ- } \\
\text { ment may be different from the } \\
\text { phenomenon occurs in the real } \\
\text { world setting. } \\
\text { - Cannot always establish the } \\
\text { random assignment (in case of } \\
\text { quasi-experimental). } \\
\text { Can lose big picture of the rela- } \\
\text { tionship among the whole range of } \\
\text { treatments. }\end{array}$ & $\begin{array}{l}\text { - Can be complicated by other } \\
\text { variables. } \\
\text { - Has better generalizability } \\
\text { than experimental has, but it is still } \\
\text { restricted to the context embedded } \\
\text { in the correlational study. } \\
\text { - Has a danger of having mul- } \\
\text { ti-variable outcomes (in case of } \\
\text { post hoc.). } \\
\text { - Does not allow researchers } \\
\text { to determine causal relationship } \\
\text { among independent and depend- } \\
\text { ent variables. }\end{array}$ \\
\hline
\end{tabular}

Correlational research facilitates analysis and prediction. Prediction, however, has less explanatory power than causal relationships inferred from the experimental design, although many of the correlational techniques which are appropriate to the evaluation of measures as predictors 
have also been used to test the validity of theoretical concepts (Crano and Brewer, 1973).

Correlational investigation encompasses several research tactics such as survey and structured interview, etc. Survey is widely used in behavioral science and architectural research. As Marans mentioned in his book, Behavioral Research and the Environment, however, there are some disadvantages of survey: costly and time consuming, low response rate and incompatibility between population under study and data collection methods (Marans, 1987).

\section{(3) Application to the Exemplar}

As mentioned in the previous chapter, direct collaboration among project participants situated in different locations is required in the early design process. Efforts have been made to encourage the development of collaborative design evaluation system to enable their use in the early design phases. A prerequisite for the increased communication and use of design technology in this stage is an interface that will allow architects to create and interact more intuitively with their schematic designs in a digital format. For instance, Virtual Reality, perhaps one of the most advanced three-dimensional presentation interfaces, has much potential for enhancing the way all participants interact with their digital models.

This is currently being realized by the Internet, which helps support a networked real-time multi-user environment. As the base for collaboration activities moves from physical space to cyberspace, the methods of connecting every participant by means of a computer application and sharing software through standardization on the network have been desired and considered. This issue is creating a growing interest in shared design evaluation system, since computer resources used by many different agencies or project teams are spread across many platforms in different locations.

The architectural design process, investigated relative to a valid time dimension, tends to be shaped with more divided, additional steps while aspects of sharing information among diverse project teams and of finalizing design agendas are considered. This new design process formed to help ensure all design issues will be addressed by all collaborating team members in search of solutions (Mendler and Odell, 2000). There are 10 key steps in the collaborative design process where considerable care and deliberation are called for:

1) Team Formation

2) Education and Goal Setting

3) Pre-Design and Information Gathering

4) Schematic Design

5) Decision-Making and Design Optimization

6) Design Development

7) Documentation and Specification

8) Bidding and Negotiation

9) Construction and Commissioning

10) Operations and Maintenance

Collaboration can happen in nearly all steps of the design process, but the collaborative design system proposed in this thesis is to be applied in the early stages; especially pre-design through design optimization, before detailed design development. The design process requires not only an architectural representation of design components, but a presentation for decision-making towards design optimization as well. The shared design evaluation system itself introduced above may not be available for an evaluation of the schematic design; accordingly, the tools of real-time communication and feedback are needed for periodic review by clients, design critics and other participants.

This mean that correalational research design is required to resolve the above stated problem; Shared evaluation system should support linking various expertise for better communication, bounding different knowledge-based comments and finalizing design agendas and decisions through collaborative survey process. When the collaborative design evaluation system consists of user-friendly interfaces for both representation and presentation, the critics, including clients, will be able to successfully evaluate design ideas. This fact explains that the exemplified research will need a specific algorithm to verify the evaluation system using additional research strategies such as simulation and theoretical approaches.

\section{QUALITATIVE AND INTERPRETIVE RESEARCH APPROACHES}

\section{(1) Characteristics of Qualitative Research Designs}

Qualitative research design usually attempts to deal with the problems that cannot be analyzed by other methods due to its complexity. "Qualitative research is multimethod in focus, involving an interpretive, naturalistic approach to its subject matter. This means that qualitative researchers study things in their natural settings, attempting to make of, or interpret, phenomena in terms of the meanings people bring to them." These issues are initially presented by Norman Denzin and Yvonne Lincoln, and Groat has addressed the characteristics of qualitative research problems based on this definition, which are:

1) the study of phenomena in their natural settings;

2) an avowedly interpretive stance on the part of the researcher;

3) a focus on how the people, observed or interviewed in the study, make sense of their circumstance; and

4 ) the use of multiple methods or tactics for data collection and analysis (Groat, 2000).

Qualitative research design basically tries to seek the qualities, which reveals the clues of a complicated phenomenon that is engaged in real life situation. In this context, Creswell states several important assumptions of the qualitative design as the following, which

1 ) is primarily concerned with process rather than product;

2) is interested in meaning;

3 ) is descriptive;

4) has the researcher as the primary instrument for data collection and analysis, rather than inventories, questionnaires, or machines; 
5) is inductive, which enables researchers to build abstractions, concepts, hypotheses and theories from details; and

6) involves field work that researcher goes to the people, setting, site or institution to observe or record behavior in its natural setting. (Creswell, 1994)

Qualitative research is typically divided into four subtypes: grounded theory, ethnography, case study and phenomenology (Groat, 2000). The grounded theory is mostly presented by Strauss, and he recently says that "In this method, data collection, analysis and eventual theory stand in close relationship to on another... Grounded theories are likely to offer insight, enhance understanding and provide a meaningful guide to action, because they are drawn from data" (Strauss and Corbin, 1998). This type of qualitative research design depends on intensive, open-ended and iterative process that simultaneously involves data collection, coding and memoing. As one of the key issues of this method, Strauss emphasizes the role of memoing by saying that "theoretical ideas are kept track of, and continuously linked and built up by means of theoretical memos ... Sorting of memos may occur at any phase of the research." He also mentions that "grounded theory" involves the multiple process of developing theory in terms of "induction" or theory conception, "deduction" or elaboration and "verification" functioning for checking out. (Strauss, 1987)

Ethnographic point of view in this method lays "particular emphasis on the immersion of the researcher in a particular cultural context, whereby the researcher seeks to ascertain the native's interpretation of his/her situation," as Groat suggests (Groat, 2000). Ethnographic work has been adopted by other disciplines, such as sociology, human geography, educational research, and organization and cultural studies, since it is relatively well consistent with the broader characteristics of qualitative research strategy, including context-rich detail, the reliance on unstructured data, a focus on a single, data analysis and so on (Atkinson and Hammersley, 1998).

On the other hand, ethnomethodological type is adopted by the empirical research approach, such as social sciences which is inspired by a phenomenological perspective. The primary focus of ethnomethodology is on the "procedures" or "processes" by which people within a given culture make sense of their reality. I think it is very interesting that Groat has compared the style of the reality in terms of ethnography and ethnomethodology; that is, "ethnography tends to assume that people within a culture are able to establish a shared reality by language, a neutral mechanism, while ethnomethodology treats "object reality as an interactional and discursive accomplishment" (Holstein and Gubrium, 1998 and Groat, 2000).

The case study is also one of practical tactics in qualitative research design. Yin regards a case study method as an empirical inquiry which "explores real-life context when the boundaries between phenomenon and context are not clearly evident, and by utilizing case study method, one can cover contextual conditions" (Yin, 1989). This strategy, however, takes a different stance from other types of quali- tative research, as Yin argues that the case study is not necessarily equivalent to qualitative research. For, the case study can rely on both qualitative and quantitative data, and it is not necessary to share some of the characteristics of other qualitative sub-types, as Groat also points out (Groat, 2000).

\section{(2) Characteristics of Interpretive Research Designs}

Interpretive research is considered to be usually on history. Tosh suggests that the interpretive research involves in two processes in history; one is the "manifest" history of stated intention and conscious preoccupation, and the other is the "latent" history of processes which "contemporaries were only dimly aware of, such as changes in demography, economic structure or deep values" (Tosh, 1991). It would be wrong to describe interpretive research as more creative in its explanations and in its relations than the other methods; but it is true that it exposes the creative process more explicitly.

It is apparent in the examples of studies that interpretive research is not only narrative and descriptive, but also structural and analytical. It is narrative, because it is able to fill in the gaps of the missing parts in the continuum of events with formal coherency. It is constructional, because it enables the researcher to show the obscure relationships of the events, not in the causal sense, but in the sense of revealing the connections, as well as giving the opportunity to show different levels of orders. Interpretive research is also analytical because it de-constructs the unity of the common knowledge in order to reveal the components, causes, and consequences, not to fold them back again after the analysis, but to employ them in another context. In this context, Tosh emphasizes that "Historians need to write in ways which do justice to both the manifest and the latent, both profound forces and surface events. And, in practice, it requires a flexible use of both analytical and narrative modes: sometimes in alternating sections, sometimes more completely fused throughout the text" (Tosh, 1991). I think Tosh's notion is important because of many needs to convey the coexistence of different levels in a single moment of historical time which incorporates different levels of expositions as narrative, description, and analysis.

All three are very connected to each other which also shows the multi-layer of interpretive research. Tosh reminds us of this issue by the works of Braudel, by saying that "He was the one who brought the solution to abandon unilinear time, a single time-scale characterized by continuity of historical development, altogether, and introduces instead the plurality of social time" (Tosh, 1991).

On the other hand, Mugerauer attempts to show how traditional, hermeneutic, and deconstructive approaches interpret the environment in the historical context. He argues the tradition is the meaning of the work in time-tested metaphors, and what we make and interpret is both a "mirror" and a "lamp," because "it reflects the reality from which it derives and creatively illuminates that reality" (Mugerauer, 1995). Hermeneutics makes the multiplicity 
of meaning possible by involving a belief that shared understanding is always possible. According to this alternative, all understanding could be interpretation, that is, contextual (Mugerauer, 1995). As Groat points out, however, an interpretive study using hermeneutics tends to be subjective due to the plurality of the meaning in it. In contrast to both traditional and hermeneutic approaches, deconstruction holds that "there is no objectively transcendent reality, no essences of things, no clear, stable, or decidable identities" (Mugerauer, 1995). In addition, there is no multiplicity, commonality, objectivity and determinacy of meaning in deconstructive approach. But, this alternative has a power to expose hidden meanings in a complicated context.

As an another example for interpretive research, Richardson \& Fowers argue that it may be helpful to classify diverse approaches to social or human science as 1) explanatory, descriptive, critical, postmodern and social construction, and 2) hermeneutic or interpretive approaches to question about the nature of human action or social. They mention that "interpretive social science or hermeneutic viewpoint offers a relatively coherent view of social inquiry that assists them in incorporating the virtues and avoiding the limitations of other approaches" (Richardson \& Fowers, 1998).

(3) Comparison of Strengths and Weaknesses

I am sure that it is possible to expose how these two research types complement each other, when strengths and weaknesses of the two methods are investigated. For qualitative designs, Groat suggests an well-organized table for analyzing strengths and weaknesses based on four qualitative sub-types (Groat, 2000).

- Qualitative research design helps try to seek the qualities, which reveals the clues of a complicated phenomenon that is engaged in real life situation.

- Interpretive research aims to address the research issue with its context that enables the researcher to explain it as a consequence or an apparent example of its time, place, culture, and community.

- Both approaches have flexibility. Qualitative research design has great capacity to modify research design as study proceeds.

- Interpretive research allows the researchers to incorporate different levels of expositions as narrative, description and analysis, and different levels of processes as manifest and latent of history.

- Qualitative research designs help gain a rich, holistic overview of the context.

- Interpretive research designs have a power to origin of systematic understanding.

- Qualitative research has a power to assess causality.

- Interpretive designs supports many-layered causation and multiple way of test.
- Qualitative research, in some instances, lacks generalizability, and is weak in external validity, as it is not very strong to show that a unique event, especially in case studies, can be generalized.

- Interpretive research, especially in the history discipline, is weak in explaining anomalies or unique events, whereas the opposite is true for qualitative research.

- Qualitative research tends to be time-consuming and labor intensive. ${ }^{3}$

- Interpretative tends to insist on objectivity and expert's judgment is often required.

Table 4. Comparison of Strengths between Qualitative and Interpretive Research Strategies

\begin{tabular}{c|c}
\hline Qualitative & \multicolumn{1}{c}{ Interpretive } \\
\hline $\begin{array}{c}\text { - Helps try to seek the qualities } \\
\text { of complex situation. }\end{array}$ & $\begin{array}{l}\text { - Aims to address the research } \\
\text { issue with its context that enables } \\
\text { the researcher to explain it as a }\end{array}$ \\
research design as study proceeds \\
consequence. \\
lism. Allows the researchers to in- \\
- Brings close relationship to & $\begin{array}{l}\text { corporate different levels of exposi- } \\
\text { tions. }\end{array}$ \\
real life situation. & Has a power to origin of sys- \\
- Is grounded to specific, com- \\
plex setting or circumstance. \\
te Has a power to assess cau- \\
sality.
\end{tabular}

Another comparison can be done on their source of knowledge and data collection. While qualitative research is very strong in gathering information as it collects data at firsthand, interpretive research may be limited with the archives. But, qualitative research has a tendency to generate overwhelming amount of data and difficulty of reducing data without losing richness. Also, methods of data analysis are less explicitly formulated.

Table 5. Comparison of Weaknesses between Qualitative and Interpretive Research Strategies

\begin{tabular}{|c|c|}
\hline Qualitative & Interpretive \\
\hline $\begin{array}{l}\text { - Lacks generalizability in } \\
\text { some instances. } \\
\text { - Tends to be time-consuming } \\
\text { and labor intensive. } \\
\text { - Has tendency to generate } \\
\text { overwhelming amount of data. } \\
\text { - Has difficulty of reducing da- } \\
\text { ta without losing richness. } \\
\text { - Has less explicitly formulated } \\
\text { methods of data analysis. }\end{array}$ & $\begin{array}{l}\text { - Is weak in explaining anoma- } \\
\text { lies or unique events. } \\
\text { - Tends to insist on objectivity } \\
\text { and expert's judgment is often } \\
\text { required. } \\
\text { - May be limited with the ar- } \\
\text { chives or data sources. } \\
\text { - Is comprehensive. } \\
\text { - Has generalizability rela- } \\
\text { tively. }\end{array}$ \\
\hline
\end{tabular}

(4) Application to the Exemplar

Just as most researches, the exemplified research can begin with the establishment of a historical and technological background in the area of design technology within

\footnotetext{
${ }^{3}$ The case study is out of this qualitative design's point of view,
} that is, not necessarily time-consuming. 
the scope of collaborative design evaluating, such as system integration, product model standardization and so on. Next, recent researches on shared information visualization technology in computer science and business area may be followed for exploration. Naturally, interpretive research designs and strategies are studied in this early phase, and it is useful to demonstrate the needs of design technology by introducing research background through various architectural events; the following shows the example of the interpretive description about the exemplar:

In 1963, Steven Coons wrote a visionary paper titled "An Outline of the Requirements for a Computer-Aided Design System" which suggested two main trends that design technology would face in order to support various design tasks, and set the research agenda in design technology for the next generation.

Currently, design evaluation systems have adequately satisfied several demands. They have dramatically improved the accuracy and consistency of working drawings, enabled designers to visualize their design ideas in threedimensions, allowed the analysis of designs through data exchange and integrated databases, and even allowed the designers to evaluate designs based on comparisons to previous cases and/or the formalization of grammars.

There is, however, a consensus that design evaluation systems have not yet achieved their full potential. First, most systems employ a single-user approach to solving architectural problems which fails to address the fact that most design work is done through teamwork. Second, current systems still cannot support early design stages which involve client briefing, data collection, building program formulation, and schematic design generation (Jabi, 1996).

On the other hand, in terms of close relationship to real life situation, qualitative research designs can be possibly used for the assumed research topic. The performance of the suggested design evaluation system needs to be compared with other existing systems, and it is needed to collect data from various architectural professions to setup criteria for an evaluation measurement of the system. Qualitative data analysis may help give a standing point of perspective to future development of the enhanced system in research and practice.

\section{THEORETICAL AND SIMULATION RESEARCH APPROACHES}

The objective of theoretical research is to develop theory through logical reasoning. It is based on the epistemological assumption that we acquire knowledge by following the sequence of logical deduction and abstraction. Such studies tend to increase general insights and to focus more on the conceptual framework of a problem than on the precise nature of particular objects or phenomena. Rather than just solving problems, what researchers want to do in theoretical studies is to systematically construct a framework of knowledge to identify and help solve new problems. Theoretical research aims to derive generalization for the future application and the activities of the re- searcher, which depend on a predetermined agenda or approach.

Theoretical studies make the investigator involve a series of steps: developing concepts, formulating hypotheses, and testing their ideas. Exploratory hypotheses are first generated on the basis of accumulated knowledge, experience and more comprehensive theories. Then these hypotheses are subject to test, because testing theories leads to the improvement and refinement of theory and to reformulate them for further testing. In theoretical research, researchers may test their hypotheses by dealing with empirical data and other hypotheses.

As Groat points out, the term, theoretical research, might be inappropriate in terms of its logic, strategies and methods. Wagner has suggested the term as "operations research," which can be defined as a scientific approach to problem-solving for executive management. In his notion, an application of operations research involves "constructing mathematical, economic and statistical models of decision problems to treat of complexity and uncertainty, analyzing the relationships that determine the probable future consequences of decision choices, and devising appropriate measures of effectiveness in order to evaluate the relative merit of alternative actions." (Wagner, 1969)

On the other hand, Winograd and Flores mention that "the rationalistic tradition is in the discipline of management science, a field concerned with mathematical analyses of decision making and with behavioral analyses of human conduct." They introduce Simon's assertion that rational decision making is a process of choosing among alternatives, and that it involves "listing all the alternative strategies, determining all the consequences that follow upon each of these strategies, and evaluating these set of consequences." (Winograd \& Flores, 1969)

Both research cases seem to have many commonalties, although they use each different term in theoretical research design. Groat points out that Winograd and Flores have implied more mental operation, perception and idea of schema called "cognition," as they mention that "There has been efforts to unify theories of human thought and language from within the rationalistic tradition under a new discipline known as cognitive science." (Winograd \& Flores, 1969)

There may also be a philosophical approach for theoretical research design. Wang claims and follows some logical sequence of arguments on the basis of philosophy and linguistics called the "Critique of judgment" in formulating the cognitive-aesthetic theory of dwelling. ${ }^{4}$ Such methodologies all share a similar characteristic, as Wang points out: "They are all attempts by the mind to construct a conceptual field, by means of systematized second order thought, to the end that any concept impinging upon the field may be rationally understood through the legislation of the contents of that conceptual field." (Wang, 1997)

\footnotetext{
${ }^{4}$ In this context, Wang introduces Roger Scruton's methodologies as philosophical methodology, linguistic analysis, critical philosophy and phenomenology.
} 
This is what a philosophical methodology attempts to do.

The main objective of simulation is to represent a system that behaves similarly to potential real world conditions. A proposed system is created in an artificial or synthetic setting, and designers observe and experience the future system in operation. The simulation process combines graphic and mental images and technical assumptions with direct experience of the system enabling the designer to interact with knowledge. By formulating a model, simulating events and analyzing results, simulation helps designers answer some basic questions about the design problems: What is involved? How will the proposed product or system be used? What constraints or external forces act upon the proposed situation? And what outcome will result from using or operating on the system? (Clipson, 1993)

The components of a simulation originate from one of three settings: the real world, the synthetic world and the virtual world setting. Each of these may be further divided into the following elements - users, operations/events and the physical environment. Researchers should carefully balance the real world, virtual and synthetic elements to achieve the necessary milieu for testing new ideas.

The real world is the world of tangible events experienced by people in everyday life. Elements of the synthetic world represent an artificial, yet physical, approximation of the real world. The virtual world is only a perceptual representation of the real world in nonphysical ways, such as computer imaginary and computer simulated operational model. Realistic techniques duplicate real world systems in both form and effect, whereas more abstract techniques assume the actions, events and conditions of a given situation. (Clipson, 1993)

Simulation techniques include full-scale mock-ups, scale models, role-play, gaming simulation, and computerassisted simulation. The combination of simulation techniques to produce a set of high fidelity operating conditions at reasonable cost is the particular challenge of simulation research design.

On the other hand, Crano \& Brewer suggest that simulation employs an imitation of processes and outcomes for clarifying or explaining the underlying mechanisms. Their point of view on this research is in the realm of social science, and the value of simulation lies in its role as a theory-testing device, rather than for the purpose of predictive accuracy. Since theories explaining and predicting the operation of real social systems will have implications for relationships in many different settings, the outcomes of simulation can provide a probe for such theories. It has the potential for "representing some of the complexities of natural settings without abandoning the manipulative control required for cause-effect interpretations of results" (Crano \& Brewer, 1973).

In addition to theory-testing, simulation research is primarily used in design process to help researchers evaluate the proposed design. Design is an anticipatory activity through which we plan for the future. It is the process by which needs, inventions, and ideas are translated into tan- gible benefits such as products, environments or systems. In order to predict and understand the future performance of the design, it is necessary to represent it during design process. Because the complexities of the real world rarely allow a complete duplication, simulation could be an applicable, effective way to provide an abstraction of actual conditions.

In sum, in theoretical research, investigators formulate conceptual models analogous to the physical models used in simulation design. Such models represent the mental schema of theory in mathematical or symbolic form, which represent abstract attributes of a concept. They help researchers put situations of complexity and uncertainty into a logical framework amenable to comprehensive analysis. By definition, mathematical models are derived in accordance with mathematical principles and present an abstract representation of real world situations. These models are also the foundation of computer simulations.

\section{(1) Comparison of Strengths}

Theoretical research is powerful in handling complex phenomena. It attempts to construct theories and systematic explanations in a reductive way, which can account for a constellation of phenomena and events. Deductive logic offers the path for drawing intelligent conclusions from existing knowledge. The role of researcher in theoretical research is to seek theoretical validation. It provides a theoretical or methodological foundation for researchers or practitioners to utilize, test and develop their logic.

Based on mathematical and computational approach, March \& Stiny have studied on shape grammars and emphasize that "In its semantic mood, the work on shape and spatial systems offers translation possibilities from one description to another description in descriptive geometry. It leads not only from one descriptive viewpoint to another, but it leads also to the possibility of precise communication between experts using different descriptive languages." (March \& Stiny, 1985) They mention that "A spatial relation is specified, whenever any collection of shape is considered, to form a recognizable arrangement that is invariant under the similarity transformations," in turn, unambiguous classification in form study may be possible through mathematical analyses dealing with shapes. (March \& Stiny, 1985)

On the other hand, Winograd and Flores assert the importance of background dealing with complex real situation rather than that of expert system, by saying, "The ideal of an objectively knowledgeable expert must be replaced with recognition of the importance of background. This can lead to the design of tools that facilitate a dialog of evolving understanding among a knowledgeable community." (Winograd \& Flores, 1969)

For the purpose of theory-testing, simulation allows for cause-effect analyses and controlled replication of variable manipulation. Compared with the experimental research conducted in laboratory, simulation studies provide considerable basis for extrapolation to the real world. To the extent that the conditions are closer to the real world set- 
ting, simulation is more generalizable. Moreover, simulation allows the exploration of multi-dimensional of independent or treatment variables. Apart from generating data for testing theories, simulation may serve valuable functions in earlier stages of theory-building. While the simulation is conducted based on some tentative theoretical background, the very process of building and operating simulations generates refinements of the theoretical structure. (Crano \& Brewer, 1973)

The main advantage of design simulation is that it offers designers the opportunity to evaluate alternative futures in an artificially created low risk setting. The impact of a design may be more accurately evaluated with a simulation that is less expensive, safer, and more user interactive that if it were tested in the real world. Simulations are used primarily to imitate the operational realities while reducing the risks associated with ineffective planning and designing. Simulations used strategically throughout the design process provide cost saving feedback. Ideas can be quickly and effectively evaluated to reshape subsequent design activity and further direct the design process. More important, evaluated design will assure the resulting solutions better satisfy technical and human performance criteria.

Simulations are effectively used where the hazards associated with real world systems are too great to support experimentation in natural setting. Use of simulation lowers or eliminates real world dangers while still developing and testing ideas. In many cases, realistic, rigorous testing of operating conditions may not be practical or ethical without simulation at various stages throughout the design process. (Clipson, 1993)

Simulation also helps designers better understand the needs of users, which is essential to good design. Because designers are frequently from different background than those for whom they design, misconception about user populations often misguide the design process. Losing sight of user needs and behaviors is a major cause of design faults. In this sense, simulations allow user groups to get involved in the design process and interact with the proposed system through participation.

Table 6. Comparison of Strengths between Theoretical and Simulation Research Strategies

\begin{tabular}{|c|c|}
\hline Theoretical & Simulation \\
\hline $\begin{array}{l}\text { - Is powerful in handling com- } \\
\text { plex phenomena. } \\
\text { - Attempts to construct theo- } \\
\text { ries and systematic explanations in } \\
\text { a reductive way. } \\
\text { - Aims to seek theoretical vali- } \\
\text { dation. } \\
\text { - Helps the researcher put the } \\
\text { complexities and possible uncer- } \\
\text { tainties into a logical framework. } \\
\text { (Model-building) } \\
\text { - Clarifies the decision alterna- } \\
\text { tives and leads to informative } \\
\text { conclusion. }\end{array}$ & $\begin{array}{l}\text { - Provides considerable basis } \\
\text { for extrapolation to the real world. } \\
\text { - Allows for cause-effect ana- } \\
\text { lyses and controlled replication of } \\
\text { variable manipulation. (Theory- } \\
\text { testing) } \\
\text { - Is more generalizable. } \\
\text { - Allows the exploration of mul- } \\
\text { ti-dimensional. } \\
\text { - Is less expensive, safer, and } \\
\text { more user interactive. }\end{array}$ \\
\hline
\end{tabular}

\section{(2) Comparison of Weaknesses}

As one of critical problems associated with theoretical study, the gap between theory and its application to further research may be considered. In addition, the process of generating theory tends to involve personal insight, experience, as well as creativity and imagination. This fact rarely allows researchers to build models which lead to the decision alternatives. Theoretical research is also difficult for establishing and validating rules, because this research ignores some criteria defining rules.

Wagner points out the limitation of operations research in a quantitative point of view. He mentions that "An operations research model is never sufficient unto itself; it cannot become entirely independent of judgment supplied by knowledgeable managers. This boundary on quantitative analysis is always manifest, because the number of questions that managers can pose is boundless, whereas the kinds of answers that a single model can provide are inherently limited." (Wagner, 1969)

The needs of the art of management science may be raised in this context. Wagner says, "The unabated expansion of quantitative analysis into previously untouched areas of decision-making is so enormous, however, that the need for imaginative and talented problem-solving will remain undiminished for some time. In turn, a considerable amount of art is still required for the successful practice of management science." (Wagner, 1969) This means that the researcher must have some facility with both the artistic and the scientific ingredients of the research subject.

While the method in theoretical research is deductive logic, simulation research makes use of induction to evaluate simulation results. One of the weaknesses of simulation research in social science is that "there is no logical basis for direct generalization from simulated social interaction to real social system." (Crano \& Brewer, 1973)

Although simulations largely reduce many real world risks, they are not completely risk free. The technical components of simulated activities, or the simulator itself may impose some hazards on participants. Perhaps more common that technical failures and model limitations are risks associated with users' incomplete understanding the underlying assumptions of a simulation. The process of planning requires users to have thorough knowledge of the systems so that they can effectively use simulation. (Clipson, 1993)

As has been noted, real world observations study some part of a system in its actual context, offering a study environment as close to actual conditions as possible. However, research in the real world carries with it costs as well as benefits, as Clipson points out; "Any introduction of synthetic element into the actual setting potentially contaminates the setting and makes objective study difficult" (Clipson, 1993).

Simulations, although varying in complexity and degree of reality, are typically simplified and abstracted representations of a more intricate real world system. The selection of elements and variables incorporated into the simulation not only determines the view of reality represented by significantly influences the resulting design or plan. Since the 
simulation may not be sufficient realistic, one disadvantage of simulation is the lack of formal validation criteria for evaluating the performance of simulated system. Researchers have to differentiate the design faults from the malfunction resulting from inadequate or inaccurate simulation. (Crano \& Brewer, 1973)

One more disadvantage of simulation research may be found in its well-known advantage called generalizability. The increase of generalizability tends to be gained with "a sacrifice of precision at the conceptual level which can only be achieved in the simpler experimental setting." (Crano \& Brewer, 1973)

Table 7. Comparison of Weaknesses between Theoretical and Simulation Research Strategies

\begin{tabular}{|c|c|}
\hline Theoretical & Simulation \\
\hline $\begin{array}{l}\text { - Has the gap between the- } \\
\text { ory and its application to further } \\
\text { research. } \\
\text { - Rarely allows researchers } \\
\text { to build models which lead to the } \\
\text { decision alternatives. } \\
\text { - Tends to involve personal } \\
\text { insight, experience and imagina- } \\
\text { tion. } \\
\text { - Is difficult to establish and } \\
\text { validate rules. } \\
\text { - Still needs the art of man- } \\
\text { agement science. }\end{array}$ & $\begin{array}{l}\text { - Are not completely risk free. } \\
\text { - May not be sufficiently realistic } \\
\text { setting and makes objective study } \\
\text { difficult. } \\
\text { - Lacks formal validation criteria } \\
\text { for evaluating the performance of } \\
\text { simulation. } \\
\text { - Lacks ethical and psychologi- } \\
\text { cal commitment. } \\
\text { - Gains generalizability with sac- } \\
\text { rifice of precision. }\end{array}$ \\
\hline
\end{tabular}

\section{(3) Application to the Exemplar}

The gaps between the conception and visualization of design ideas tend to hinder direct or immediate feedback in the collaborative design process. However, the simulations on the network can provide a method to examine the design model during the design development, to detect flaws which may occur in future construction, and give an opportunity to evaluate design elements such as proportion, scale, and order; things that are not readily apparent to designers using traditional design models alone. In addition, Object-Oriented programming and methodology can be modeled after real world objects to reduce the cognitive burden. As mentioned in the previous strategies, the use of design technology associated with Object-Oriented programming for simulation early in the design process can force the detailed development of the design idea to proceed more easily and effectively.

As one of important parts of the suggested research, low-level computer languages are needed for the system implementation. By using these programming languages, it is possible for input and feedback to pass through an intermediary information modeler. Because these programming languages deal with many arithmetic algorithms forming a computational application, they are applicable to this research in the category of theoretical research strategies.

In addition, simulation research designs can also be used for the research. The performance of the design evaluation system needs to be examined with a three-dimensional information presentation system, which can be simulated as a prototype model maintained in the modeler. Other design technologies, such as Virtual Reality and Building Information Modeling technology may be further explored in order to accomplish system feasibility in the future research.

\section{CONCLUSION}

This paper aims at evaluating research design strategies to be used in the area of architectural design research. To discuss about the applicability of the design methods employed, it is needed to assume that there is a composite topic to resolve the research questions; how to develop a design evaluation system and what to be considered for unfolding the thrown topic in terms of strategic approaches. For this research, shared interactive design evaluation system with three-dimensional information modeler has been suggested as an exemplar used for verifying the results of comparative study on research design methods supporting the requirements to meet the architectural design process.

To accomplish this research objective, it is necessary to gather information on the interaction between related research on the design process and supporting design technologies, especially followed both in computer science and in the business fields. As one of initial investigations for the research, structured interviews and questionnaires will be possible to apply for both design students in school and practitioners in the profession, to find out their experiences of either computer-aided or manual-based design evaluation into typical design process. With possible use of survey strategy and careful observation, more detailed research data can be obtained and analyzed by the correlational means of research designs for further analyses.

After the surveys, this research will begin with the establishment of a historical and technological background basis in the area of design technology within the scope of collaborative design evaluating focused on system integration and product model standardization. Interpretive research designs and strategies will involve in this early phase, and it may useful to demonstrate the needs of architectural design technology by introducing the facts of architectural history and events, although this approach cannot be fully applied for developing the main research idea.

On the other hand, because of the characteristic of technology-based research, experimental approach seems rather applicable for this research area. For example, use of computer languages for the system implementation might be an essential part of the research, and similar action of dealing with outcomes as dependant variables will be performed in well-organized computing environments like under well-controlled laboratory settings. Especially, with these programming languages, input and feedback can pass either through an intermediary information modeler. Because they deal with many arithmetic algorithms forming computational applications, I am sure that they are in the category of theoretical research strategies and may applicable to the suggested research topic. 


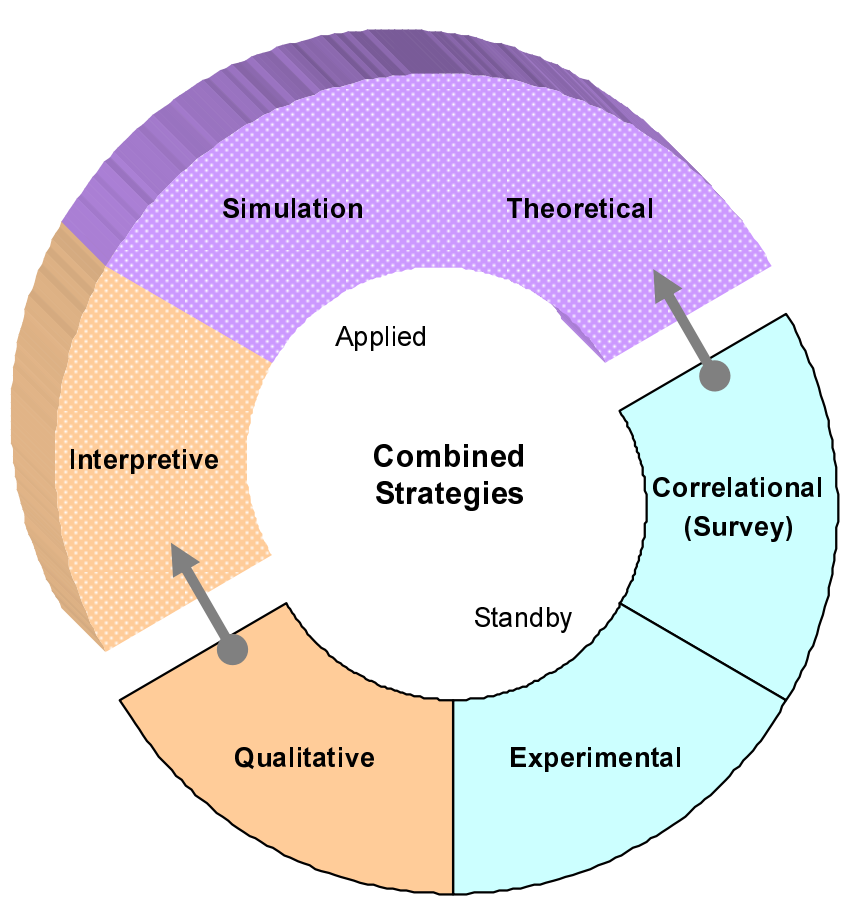

Figure 1. The Scope of Applied Research Designs to Examplified Research Theme, Development of a Design Evaluation System

By investigating the suggested exemplar with combined research strategies, it has been revealed that multispecializations in the AEC (Architecture, Engineering and Construction) industries make the process of building design more time-consuming and complicated. It is also made difficult when architects and other specialists are physically located in different places and are usually working on different design models. There can certainly be many scenarios while design activities are in process, yet it is meaningful to investigate a typical case of collaboration in the early design stage.

It is very difficult to have a clear vision of the overall quality of the design project among the participating specialists. Due to their limited points of view in a different discipline, each specialist tries to optimize the design for his/her own discipline, which conceivably may come at the expense of other disciplines. What is really needed to bring the various specializations together into a coherent whole is an effective collaborative design evaluation system. This calls for the development of an environment within which all the building design professionals can work together; so that there are no delays, inconsistencies, miscommunications, and other errors while evaluating the design alternatives. This environment also has to provide a means to negotiate partial solutions, to trade them off against each other so the overall result is improved. Essentially, the communicative evaluation environment has to recognize the significance of collaboration in enhancing the quality of building design, and be geared towards actively fostering and providing for that goal.

In addition, in terms of close relationship to real life situation, qualitative research designs can be positively used for the exemplar research topic. The performance of the design evaluation system needs to be compared with other systems using qualitative research methods, and it is needed to collect data from various architectural professions to setup criteria for an evaluation measurement of this prototype system. Qualitative data analyses may help give a standing point of perspective to future development of the system in research and practice.

For theory-testing, simulation research designs can be also used for the given research topic. The performance of the design evaluation system needs to be examined with three-dimensional information presentation system, which can be tested as a prototype model on the Web. Virtual Reality technology and Building Information Modeling will possibly be further explored in order to accomplish system feasibility in the future research.

\section{ACKNOWLEDGEMENTS}

This work was supported by the Grant of the Korean Ministry of Education, Science and Technology(The Regional Core Research Program/Biohousing Research Institute).

\section{REFERENCES}

Atkinson, P. and Hammersley, M., "Chapter 5: Ethnography and Participant Observation," In Denzin, N. and Lincoln, Y. (eds.) Strategies for Qualitative Inquiry, Thousand Oaks, CA: Sage Publications, Inc., pp. 110136, 1998.

Blalock, H., "Chapter 1: Introduction" and "Chapter 2: Theory, Measurement and Mathematics," Social Statistics. New York: McGraw-Hill Book Co., pp. 3-21, 1960.

Brenner, M., Brown, J. and Canter, D., "Introduction," The Research Interview. London: Academic Press, pp.1-8, 1985.

Boyer, E. and Mitgang, L., "Building Community: A New Future for Architecture Education and Practice", Princeton, NJ: Carnegie Foundation, 1996.

Clipson, C., "Simulation for Planning and Design: A Review of Strategy and Technique," In R. W. Marans and D. Stokols (eds.) Environmental Simulation: Research and Policy Issues, New York: Plenum Press, pp.116-135, 1993.

Cook, T.D. and Campbell, D.T., "Chapter 1: Causal Inference and Language of Experimentation," QuasiExperimentation: Design and Analysis. New York: Houghton Mifflin, pp. 1-36, 1979.

Coons, S. "An Outline of the Requirements for a Computer-Aided Design System", Proceedings of the Spring Joint Conference, Detroit, Michigan, May 1963, 1963.

Crano, W. and Brewer, M., "Chapter 5: Correlational Design," Principle of Research in Social Psychology. New York: McGraw-Hill Book Co., pp. 90-113, 1973.

Creswell, J.W., "Research Design: Qualitative \& Quantitative Approaches," Thousand Oaks, CA: Sage Publications Inc., pp.116-135, 1994. 
Groat, L. N., "Chapter 6: Qualitative and Case Study Research: Understanding Complex Situations in Context," Pre-published Material Used for Architecture 813, Ann Arbor, MI: The University of Michigan, pp. 1-19, 2000.

Groat, L. N., "Analytical Matrices for Theoretical / Simulation Research," In the Class of Architecture 813, Ann Arbor, MI: The University of Michigan, Winter, 2000.

Han, S., "Working Prototype of Distributed Collaborative Architectural Design System", Dissertation for the Degree of Ph.D., The University of Michigan, Ann Arbor, Michigan, 2004.

Holstein, J. and Gubrium, J., "Phenomenology, Ethnomethodology, and Interpretive Practice," In Denzin, N. and Lincoln, Y. (eds.) Strategies for Qualitative Inquiry, Thousand Oaks, CA: Sage Publications, Inc., pp. 137157, 1998.

Isaac, J. and Michael, W., "Chapter 3: Guide to Research Designs, Methods and Strategies," Handbook in Research and Evaluation. San Diego: EDITS Publishers, pp.41-55, 1981.

Jabi, W. "An Outline of the Requirements for a ComputerSupported Collaborative Design System", in Open House International, vol 21, no 3, 1996.

Lansdown, J., "Visualizing Design Ideas", in Interacting with Virtual Environments, John Wiley \& Sons, Inc., Chichester, England, 1994.

Lawrence, R., "A Psychological-Spatial Approach for Architectural Design," Journal of Environmental Psychology, 2(1), pp. 37-51, 1982.

Marans, R., "Chapter2: Survey Research," Behavioral Research and the Environment. New York: Van NostrandReinhold, pp.41-81, 1987.

March, L. and Stiny, G., "Spatial Systems in Architecture and Design: Some History and Logic," Environment and Planning B: Planning and Design, Vol. 12, pp. 31-53, 1985.

McGinty, T., "Design and the Design Process", in Introduction to Architecture, McGraw-Hill, New York, 1979.

Moon, J., "ANN-Based Model-Free Thermal Controls for Residential Buildings", Dissertation for the Degree of Ph.D., The University of Michigan, Ann Arbor, Michigan, 2009.

Mugerauer, R., "Introduction," Interpreting Environments: Tradition, Deconstruction, Hermeneutics, Austin, TX: University of Texas Press, pp. xv-xlvi, 1995.

Preziosi, D., "The Question of Art History," In J. Chandler, A. Davidson and H. Harootunian (eds.) Questions of Evidence: Proof, Practice and Persuasian across the Disciplines, Chicago, IL: The University of Chicago Press, pp. 203-206, 1994.

Richardson, F. and Fowers, B., "Interpretive Social Science," American Behavioral Scientist, Vol. 41, No. 4, pp. 465-495, 1998.

Stamps, A. E., "Simulation Effects on Environmental Preference," Journal of Environmental Management, 38, pp. 115-132, 1993.Strauss, A. L., "Chapter 1: Introduction," Qualitative Analysis for Social Scientist, New York, NY: Cambridge University Press, pp. 1-22, 1987.
Strauss, A. and Corbin, J., "Grounded Theory Methodology: an overview," In Denzin, N. and Lincoln, Y. (eds.) Strategies for Qualitative Inquiry, Thousand Oaks, CA: Sage Publications, Inc., pp. 158-183, 1998.

Tosh, J., "Chapter 6: Writing and Interpretation" and "Chapter 9: History by the Numbers," The Pursuit of History, London, England: Logman, pp. 110-129, 1991.

Wagner, H. M., "Chapter 1: The Art and Science of Executive Decisions," Principals of Operations Research with Applications to Managerial Decisions, Englewood Cliffs, NJ: Prentice-Hall Inc., pp. 3-14, 1969.

Wang, D. C., "A Cognitive-Aesthetic Theory of Dwelling: Anchoring the Discourse on the 'Concept of Dwelling' in Kant's Critique of Judgement," Ph.D. (Architecture) Dissertation, Ann Arbor, MI: The University of Michigan, pp. 1-19, 1997.

Winograd, T. and Flores, F., "Chapter 2: The Rationalistic Tradition" and "Chapter 6: Towards a New Orientation," Understanding Computers and Cognition, Reading, MA: Addison-Wesley Publishing Co., Inc., pp. 14-26; 70-79, 1969.

Yin, R. K., Case Study Research, Newbury Park, CA: Sage Publications, Inc. pp. 13-45, 1984, 1989.

Zeisel, J., "Chapter 5: Research Strategy: Approaches, Designs Settings" and "Chapter 6: Research Quality," Inquiry by Design. New York: Cambridge University Press, pp. 59-86, 1981.

(Date of Submission : 2010.8.9) 